\title{
An assessment of the potential for shower water heat recovery
}

\author{
Sabina Kordana ${ }^{1, *}$ \\ ${ }^{1}$ Rzeszow University of Technology, Department of Infrastructure and Water Management, \\ al. Powstańców Warszawy 6, 35-959 Rzeszów, Poland
}

\begin{abstract}
The recovery of heat from greywater is one of the methods for reducing the energy demand on buildings. The process may be accomplished, e.g. using a Drain Water Heat Recovery (DHWR) unit installed at the shower drain. The paper analyzes the rationale for a DWHR unit being installed within a joint drain system of two separate shower installations. To this end, Net Present Values $(N P V)$ and Profitability Indexes $(P I)$ were calculated for the different parameters of a building shower operation. The study showed that the profitability of such investment depends not only on the installation's operation parameters but also on the type of energy carrier.
\end{abstract}

\section{Introduction}

Numerous technologies and practices in use today may bring harm to humans and the environment $[1,2]$. The adverse effects can be associated with the use of substances that pollute the air, water and other natural resources [3-5] as well as the operation and maintenance of urban infrastructure [6,7]. The problem is also encountered in the construction and use of housing and commercial buildings, and relevant changes are being implemented accordingly $[8,9]$. Some of the most important changes consist of reducing the consumption of water and energy in individual facilities [10,11] as well as in the minimized adverse environmental impact of various solutions $[12,13]$. Such an approach may undoubtedly be referred to as sustainable and efforts should be made to maintain this sustainability in longer time frames. However, one must keep in mind that appropriate living and working standards should remain the main determinant taken into account when choosing appropriate solutions in construction engineering as well as in other areas $[14,15]$.

One of the methods to reduce the energy demand of buildings is to reduce the energy being consumed for water heating purposes [16]. A major part of the technologies used worldwide consists of improving the thermal efficacy of heat sources [17] and in using appropriate tapping fittings [18]. Other solutions are based on the possibility of replacing fossil fuels with non-conventional energy sources such as renewable and waste energy sources [19].

\footnotetext{
${ }^{*}$ Corresponding author: sk@prz.edu.p1
} 
One of the feasible waste energy carriers is the greywater from shower drains [20, 21]. The energy contained in greywater may be recovered using heat pumps or Drain Water Heat Recovery (DWHR) units. However, the validity of implementing any of these solutions depends on a number of parameters including, among others, the installation size and operation regimen. In response to this issue, this paper presents the results of an analysis comparing the profitability of DWHR units being used in shower installations with different use profiles.

\section{Theory and calculation}

Besides providing a valuable source of water for non-potable purposes [22], greywater drained from sanitary facilities may also be used as a non-conventional source of energy, e.g. for water heating [23]. In order to recover the heat accumulated in greywater, appropriate installations built within buildings may include retention systems for waste or heated water as well as non-storage DWHR units. The latter are particularly recommended when the energy for water heating is recovered from greywater being drained from shower installations and when instantaneous heaters are used for water heating purposes. In such systems, greywater at a temperature between $35-40^{\circ} \mathrm{C}$ may be used for the further heating of water used during the same shower. This allows for reducing the unnecessary losses of heat due to greywater drained from the shower installation being accumulated and transported on longer distances.

To date, studies on the profitability of DWHR units in building installations usually focused on the heat exchange system being used in a single shower installation $[19,24]$. In this study, the rationale for using a common DWHR unit for two separate shower installations within the same building was analyzed (Fig. 1). To this end, a computational model allowing for the estimation of potential energy savings as described in [24] was used along with the data on the efficacy of a model vertical heat exchange system as provided by the system manufacturer. The possibilities of both showers being used independently as well as simultaneously were considered. In addition, a wide range of total daily shower use periods $(p)$, and different mixed water flow rates from the shower heads $\left(q_{w m}\right)$ of 5,6 , and $7 \mathrm{~L} / \mathrm{min}$ were taken into consideration. Due to the limited flow capacity of the DWHR unit, the impact of other tap fittings was could be neglected and was not taken into account into analysis. The analysis was carried out for two different types of energy carriers:

- variant 1 - electricity,

- variant 2 - natural gas.

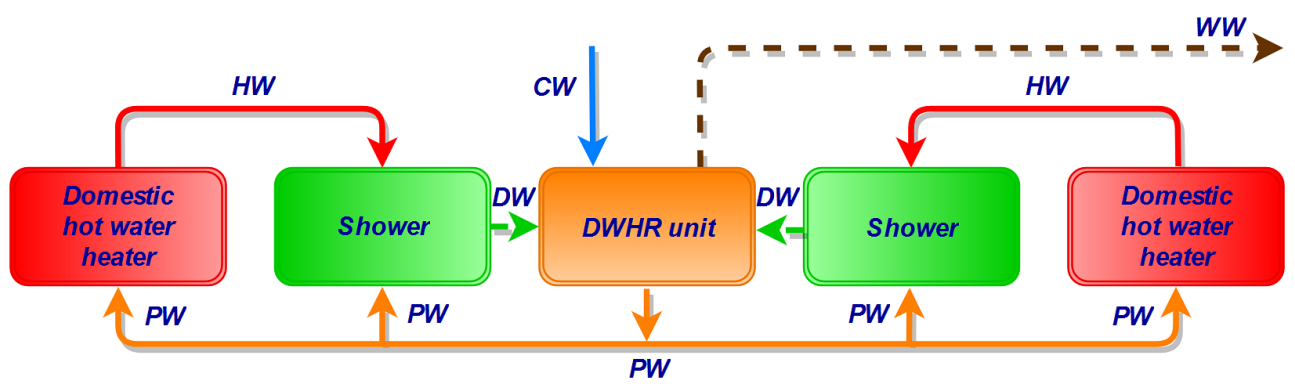

Fig. 1. Diagram of the installation: $C W$ - cold water from the water supply system, $D W$ - drain water, $H W$ - hot water, $P W$ - preheated water, $W W$ - wastewater discharge from the building.

The assessment of the profitability of the investment was based on the determination of Net Present Values (NPV) and Profitability Indexes $(P I)$ [25] on the assumption that the characteristics of operation of both shower systems were exactly the same. The Net Present 
Value allows for determination of the difference between positive discounted cash flows, i.e. the savings being generated, and the negative discounted cash flows, i.e. the investment costs. The Profitability Index is the ratio of both these cash flows. An investment is deemed profitable when $N P V>0$ and $P I>1$, and the potential financial benefits increase along with both these values. Furthermore, Discounted Payback Period (DPP) was calculated for different installation operating conditions.

The values of the input parameters are the following:

- shower operation time ( $p$ ): 0-100 min (for one shower),

- mixed water flow rates from the shower heads $\left(q_{w m}\right): 5,6$ and $7 \mathrm{~L} / \mathrm{min}$,

- the total cost of the purchase and assembly of a DWHR unit in the year $0\left(I N V_{0}\right)$ : $€ 750$,

- the discount rate $(r): 5 \%$,

- the lifetime of a DWHR unit $(n): 15$ years,

- the price of electricity in the year $0\left(C_{e 0}\right): 0.136 € / \mathrm{kWh}$,

- the price of natural gas in the year $0\left(C_{g 0}\right): 0.043 € / \mathrm{kWh}$,

- annual increase in energy carriers prices $\left(i_{e}\right): 1 \%$,

- hot water temperature $\left(T_{h w}\right): 60^{\circ} \mathrm{C}$,

- cold water temperature $\left(T_{c w}\right): 10^{\circ} \mathrm{C}$,

- mixed water temperature $\left(T_{m w}\right): 40^{\circ} \mathrm{C}$,

- drain water temperature $\left(T_{d w}\right): 38^{\circ} \mathrm{C}$,

- electric water heater efficiency $\left(\eta_{e}\right): 0.95$,

- natural gas water heater efficiency $\left(\eta_{e}\right): 0.80$.

A sensitivity analysis was also carried out to evaluate the impact of changes in the parameters assumed for calculation purposes on the financial efficiency of the investment. This analysis was required due to the high differentiation of energy carrier prices and tariffs and the unpredictability of price fluctuations over the years of use.

\section{Results and discussion}

Figure 2 presents the results of $N P V$ calculations for the study installation depending on different shower usage time assumptions. Orange lines indicate the ranges of $N P V$ values obtained for gas water heaters while red lines indicate the ranges of $N P V$ values obtained for electric water heaters. The lines indicating the lower limits of both ranges correspond to the assumption of water being drained simultaneously from both tapping points while the lines indicating the upper limits of both ranges correspond to the assumption of water being drained from only one tapping point at a time. For the sake of comparison, lines corresponding to $N P V$ values obtained in the case of two separate DWHR units being used were also plotted on the graph. Green lines correspond to heat exchangers working with gas-powered devices while blue lines correspond to heat exchangers working with electric devices. Intersections of lines are marked with yellow points.

As shown by the results, systems for the recovery of heat from greywater are more profitable in buildings equipped with electric water heaters (variant 1). This is associated with the costs required to provide the building with energy to be consumed for water heating purposes. The unit price is higher for electric energy as compared to gas fuel, and therefore potential savings associated with the use of DWHR systems would also be markedly higher in this case. Depending on the shower operation times $(p)$ and the mixed water flow rates $\left(q_{w m}\right)$, the Net Present Value of the analyzed investment may be as high as several thousand euros. Negative $N P V \mathrm{~s}$ were obtained only for short daily operation times of about 5 to nearly $13 \mathrm{~min}$ depending on $q_{w m}$ and the number of heat exchangers. Considering that the average water consumption for showering in Poland is about $35 \mathrm{~L}$ per person per day, one may assume that the financial benefits would balance the investment costs already for an installation being used by a family of three. 


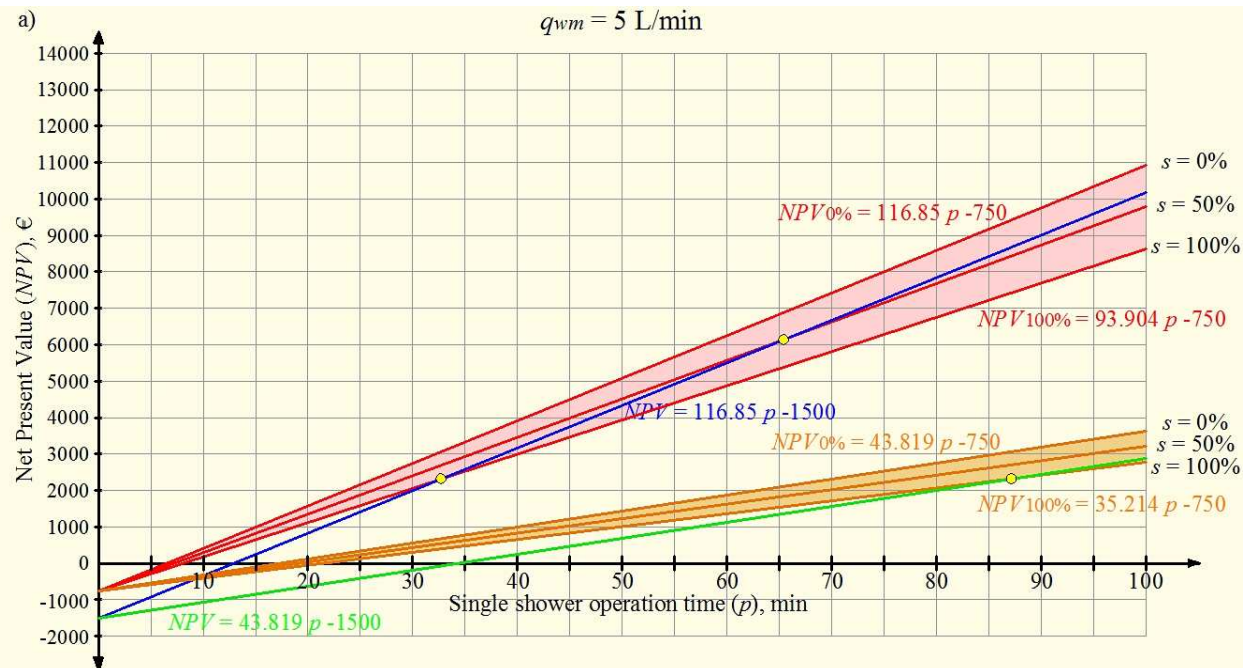

b)

$q w m=6 \mathrm{~L} / \mathrm{min}$

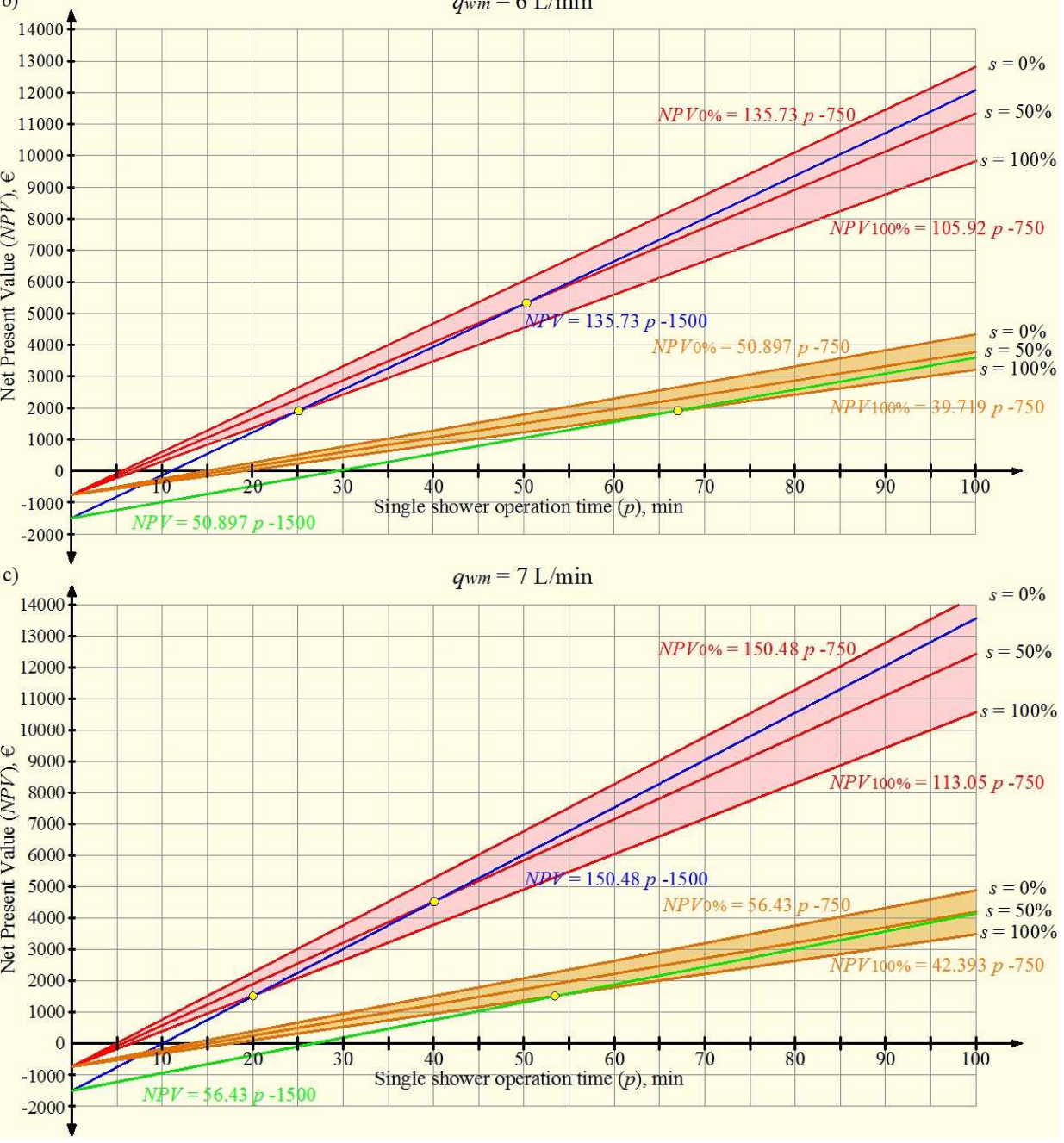

Fig. 2. Results of the $N P V$ analysis ( $s$ - simultaneous vs. total use ratio). 
If gas heaters are used for heating water (variant 2), the potential savings are not as high as in the previous variant. The maximum $N P V$ value obtained for the assumed non-simultaneous use of both tapping points, single shower installation operation time of $p=100 \mathrm{~min}$ and mixed water flow rate from the shower head of $q_{w m}=7 \mathrm{~L} / \mathrm{min}$ does not exceed $€ 4,900$. At the same time, each option involving the use of electric water heaters allows the savings obtained for the same $p$ and $q_{w m}$ values to exceed the investment costs by more than $€ 10,000$. For the lowest mixed water flow rate of $q_{w m}=5 \mathrm{~L} / \mathrm{min}$ and operation time of $p=100 \mathrm{~min}$, the $N P V \mathrm{~s}$ exceed $€ 2,700$ for variant 2 and $€ 8,600$ for variant 1 . Discounted Payback Period for the investment involving DWHR unit(s) operating along with gas water heaters and $p=100 \mathrm{~min}$ is between almost 2 and more than 4 years. If water is to be heated with electrical devices, the DPP may be as short as several months.

For the shorter average operation time of $p=25 \mathrm{~min}$, Discounted Payback Period of the investment variant 2 may extend to more than 12 years for a single DWHR unit or exceed the technological lifetime of the device for two separate DWHR units. In such a case, the use of a single heat exchanger may generate slight benefits not exceeding several hundred euros. On the other hand, an investment involving two separate DWHR units would be unprofitable since positive $N P V \mathrm{~s}$ are obtained for variant 2 only when the total time of operation $(p)$ of a single shower system is longer than about $26.5 \mathrm{~min}$ for $q_{w m}=7 \mathrm{~L} / \mathrm{min}$, $29.5 \mathrm{~min}$ for $q_{w m}=6 \mathrm{~L} / \mathrm{min}$ and $34 \mathrm{~min}$ for $q_{w m}=5 \mathrm{~L} / \mathrm{min}$.

As also demonstrated by the analysis, the validity of the solution involving a common DWHR unit being installed for two separate shower systems depends on the energy carrier being used in the building. In the case of gas-powered water heating, the cost of purchasing a DWHR unit is inadequately high as compared to annual water heating costs. As a consequence, installations with relatively low water consumption are characterized by higher $N P V \mathrm{~s}$ when a common heat exchanger is used for separate shower systems. The only case when $N P V \mathrm{~s}$ obtained for two separate DWHR units are not the lowest of these presented in Figure 2 is that of long total daily operation times exceeding from 53.5 to 87 min per day depending on the mixed water flow rate. It is also worth mentioning that this is only the case when the time ratio of simultaneous vs. total shower use is high.

As energy prices increase, so does the benefit of using separate DWHR units as compared to a single common unit. Consequently, separate heat exchangers may be more profitable in facilities equipped with electrical water heaters and characterized by long total daily times of use, such as sporting facilities or fitness clubs. In the case of larger facilities characterized by water uptake times longer than these included in the analysis, separate DWHR units may also be profitable in gas-powered heating installations. However, such solution would require detailed technical and financial analysis of potential investment variants.

Meanwhile, the obtained $P I$ values suggest that a single common DWHR unit is more predictable in financial terms, as shown in Figure 3. Due to the linearity of the relationship between $P I$ and the shower installation operation times $p$, and to the lack of intersections between the plotted lines, the range of operation times presented in the plots was limited to $p=25$ min. Color markings are analogous to these in Figure 2. As shown by the analysis, a single heat exchanger being used for two separate shower installations facilitates a significant reduction of investment costs relative to the expected savings. As a result, the risk of investment failure due to an unexpected reduction in energy unit prices is markedly reduced. This is also confirmed by the results of $D P P$ calculations. The use of a common heat exchanger is characterized by faster return on investment, with lower DPPs being obtained for lower simultaneous vs. total use ratios. 

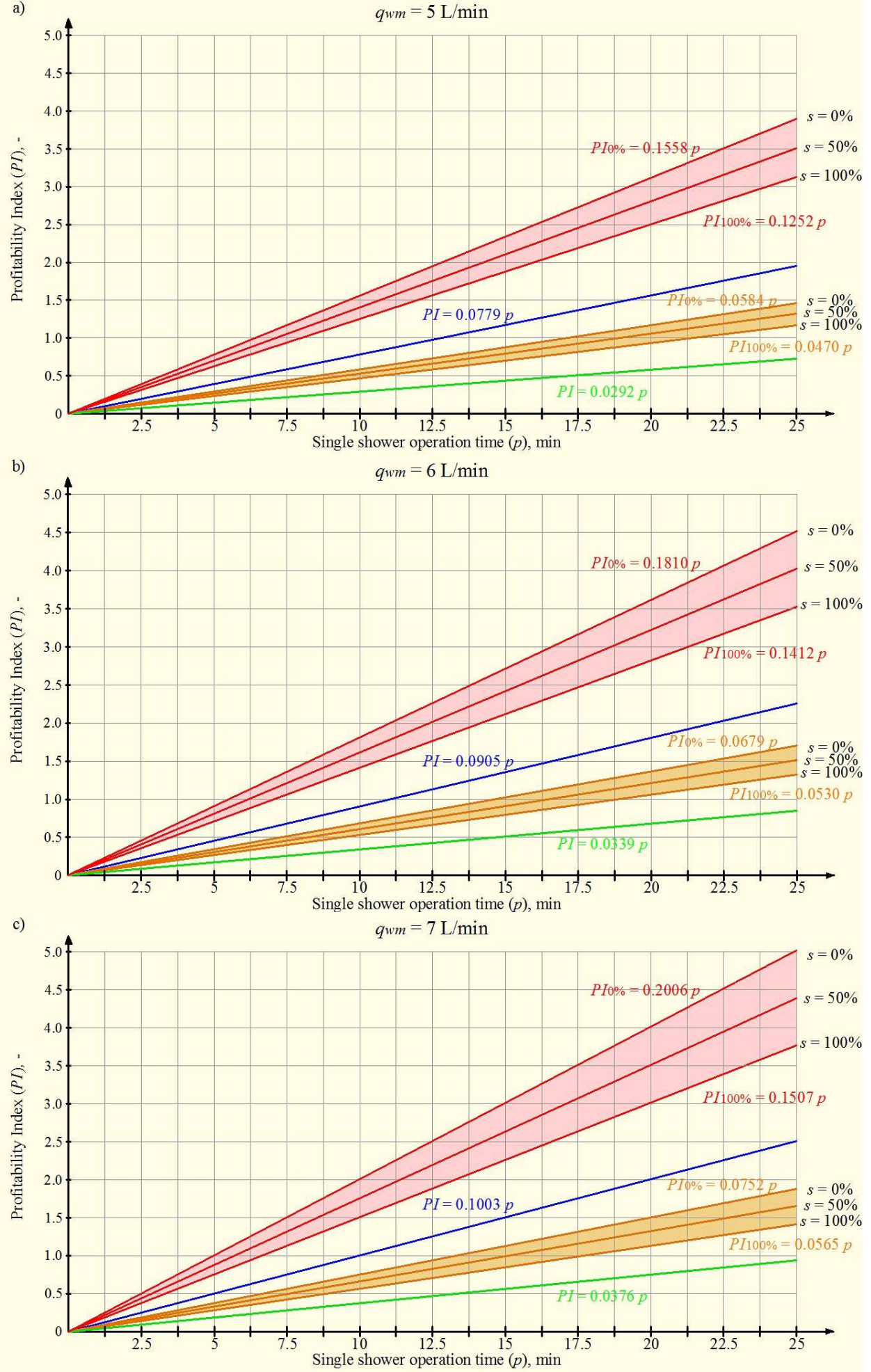

Fig. 3. Results of the $P I$ analysis ( $s-$ simultaneous vs. total use ratio). 
A sensitivity analysis was also carried out as part of the study. The impact of potential changes in investment expenditures $\left(c_{1}\right)$ and energy unit prices $\left(c_{2}\right)$ on the profitability of the investment was examined. The importance of the simultaneous operation of both tapping points in the single DWHR unit variant was also analyzed. Due to the extensive scope of the analysis, only a part of the results are presented in this article. Figure 4a presents the sensitivity curves determined for the average mixed water flow rate of $q_{w m}=6 \mathrm{~L} / \mathrm{min}, 50 \%$ simultaneous vs. total use ratio and shower system operation times of $p=25 \mathrm{~min}$ and $p=100 \mathrm{~min}$. Red lines correspond to the first variant involving DWHR units operating along with electrical water heaters while orange lines correspond to the second variant involving DWHR units operating along with gas-powered water heaters. As shown by the results of the analysis, variant 2 is more sensitive towards potential changes in the independent variables. At short operation times, a 34\% reduction in natural gas prices and a $50 \%$ increase in investment expenditures may cause the $N P V$ to fall below 0 . On the other hand, the relative safety margins as determined for energy prices in variant 1 are much larger and amount to $-75 \%$ and $-94 \%$ for $p=25 \mathrm{~min}$ and $p=100 \mathrm{~min}$, respectively. In case of the investment expenditures, the respective values are as high as $303 \%$ and $1511 \%$. The use of two separate heat exchangers (blue and green lines, respectively for electric and gas water heaters) results in a significant reduction of relative safety margins in both investment variants.

Figure $4 \mathrm{~b}$ illustrates the impact of simultaneous vs. total use ratio on the predicted profitability of the investment. Also in this case, the results are presented for the average flow rate of $q_{w m}=6 \mathrm{~L} / \mathrm{min}$ and operation times of $p=25 \mathrm{~min}$ and $p=100 \mathrm{~min}$. As shown in the figure, the longer the operation time, the higher the impact of simultaneous use on the financial efficiency of the investment. This confirms that separate DWHR units may be beneficial in installations characterized by longer water uptake times.
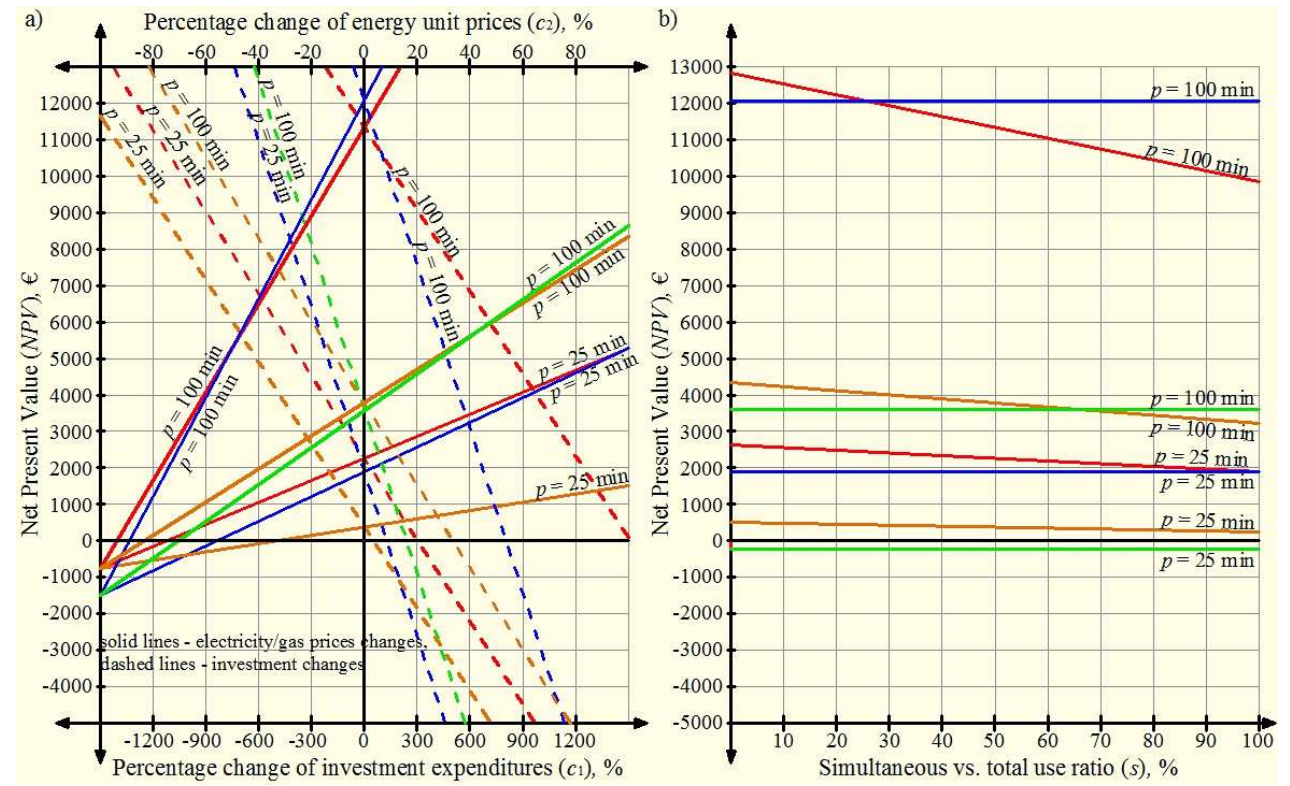

Fig. 4. Results of sensitivity analysis.

\section{Conclusions}

The analysis of the rationale for the use of a greywater heat recovery system presented in this study shows that potential financial benefits depend on the installation operation 
profiles, the type of the energy carrier, and the number of DWHR units installed. A common heat exchanger being used for two separate shower systems may reduce the risk associated with an unexpected reduction in savings as compared to the predicted values and facilitates significant reduction in the Discounted Payback Period. However, the installation of two separate DWHR units may prove more profitable when shower installations are to be used for longer times. Therefore, detailed technical and financial analysis of available investment options should be performed on a case-by-case basis.

\section{References}

1. V. Mikhailov, T. Kiseleva, S. Bugrova, A. Muromtseva, Y. Mikhailova, E3S Web Conf. 21, 02004 (2017)

2. M. Starzec, J. Dziopak, D. Słyś, Underground Infrastructure of Urban Areas 4, 193-200 (2018)

3. J. Kaleta, M. Kida, P. Koszelnik, D. Papciak, A. Puszkarewicz, B. TchórzewskaCieślak, Arch. Environ. Prot. 43, 32-41 (2017)

4. L. Bartoszek, P. Koszelnik, R. Gruca-Rokosz, M. Kida, Rocz. Ochr. Sr. 17, 396-409 (2015)

5. S. Rabczak, D. Proszak-Miąsik, J. Ecol. Eng. 17, 186-191 (2016)

6. K. Pochwat, D. Słyś, S. Kordana, J. Hydrol. 549, 501-511 (2017)

7. H. Wang, C. Mei, J.H. Liu, W.W. Shao, Sci. China Technol. Sc. 61, 317-329 (2018)

8. D. Słyś, A. Stec, Ecol. Chem. Eng. S 21, 623-635 (2014)

9. D. Słyś, A. Stec, M. Zeleňáková, Ecol. Chem. Eng. S 19, 359-372 (2012)

10. A. Bertrand, R. Aggoune, F. Maréchal, Appl. Energ. 192, 110-125 (2017)

11. E. Wanjiru, X. Xia, J. Clean Prod. 170, 1151-1166 (2018)

12. D. Kaposztasova, Z. Vranayova, G. Markovic, P. Purcz, Procedia Engineer. 89, 1500-1506 (2014)

13. A.K. Marinoski, R.F. Rupp, E. Ghisi, J. Environ. Manage. 206, 28-39 (2018)

14. K. Pochwat, E3S Web Conf. 17, 00075 (2017)

15. M. Starzec, J. Dziopak, Underground Infrastructure of Urban Areas 4, 181-191 (2018)

16. S.E.D. Fertahi, T. Bouhal, F. Gargab, A. Jamil, T. Kousksou, A. Benbassou, Sol. Energy 160, 260-274 (2018)

17. A. Mazur, D. Słyś, E3S Web Conf. 17, 00058 (2017)

18. A.P. Svintsov, M.I. Kharun, S.A. Mukarzel, Mag. Civil Eng. 58, 8-18 (2015)

19. A. Stec, A. Mazur, D. Słyś, E3S Web Conf. 22, 00168 (2017)

20. K. Ip, K. She, K. Adeyeye, Environ. Sci. Pollut. R. (2017) https://doi.org/10.1007/s11356-017-0409-0

21. R. Manouchehri, M.R. Collins, Energ. Buildings 165, 150-159 (2018)

22. E. Wanjiru, X. Xia, Sustain. Cities Soc. 32, 654-668 (2017)

23. T. Gabor, V. Dan, I.N. Badila, A.E. Tiuc, I.M. Sur, Environ. Eng. Manag. J. 16, 1631-1636 (2017)

24. D. Słyś, S. Kordana, Energ. Buildings 71, 1-11 (2014)

25. J.C. Van Horne, J.M. Wachowicz, Jr., Fundamentals of Financial Management (Prentice Hall/Pearson Education Limited, Harlow, 2009) 